\title{
Map and Tables
}

\section{Map}

\section{Tables}

Geneva and Its Territories in the Mid-Eighteenth Century. ........9

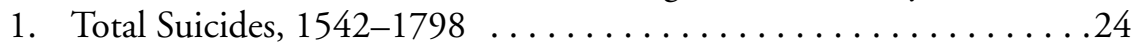

2. Suicide Rates per 100,000 in Early Modern Geneva24

3. Questionable Unnatural Deaths, 1542-1798. . . . . . . . . . . 27

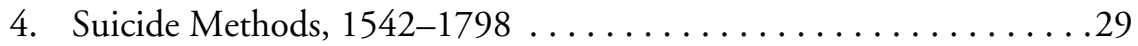

5. Deaths by Firearms, $1542-1798$. . . . . . . . . . . . . . . . . .29

6. Suicides by Gender, $1542-1798 \ldots \ldots \ldots \ldots \ldots \ldots \ldots \ldots \ldots \ldots$

7. Suicide Method and Gender, $1542-1798 \ldots \ldots \ldots \ldots \ldots \ldots . \ldots \ldots$

8. Firearm Deaths, Excluding Suicides, $1542-1798 \ldots \ldots \ldots \ldots \ldots 36$

9. Deaths by Drowning, $1542-1798 \ldots \ldots \ldots \ldots \ldots \ldots \ldots \ldots \ldots \ldots$

10. Deaths by Drowning, Excluding Suicides, $1542-1798$. . . . . . . 39

11. Accidental Drownings Involving Adults, $1542-1798 \ldots \ldots \ldots \ldots .40$

12. Questionable Drownings, $1542-1798 \ldots \ldots \ldots \ldots \ldots \ldots \ldots \ldots \ldots$

13. Deaths from Falls, $1542-1798 \ldots \ldots \ldots \ldots \ldots \ldots \ldots \ldots \ldots 4$

14. Deaths from Falls Involving Children, $1542-1798 \ldots \ldots \ldots \ldots .45$

15. Deaths from Poisoning, $1542-1798$. . . . . . . . . . . . . . 49

16. Average Age of Suicides According to Gender and Method, 1542-179849

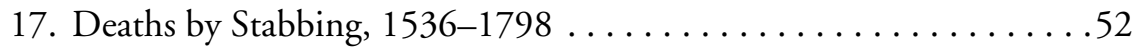

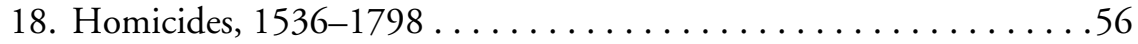

19. Involuntary Manslaughter, $1542-1798 \ldots \ldots \ldots \ldots \ldots \ldots 6$

20. Questionable Infant Deaths, $1542-1798 \ldots \ldots \ldots \ldots \ldots \ldots \ldots$

21. Infant Roll-Over Deaths, $1542-1798$. . . . . . . . . . . . . . 59

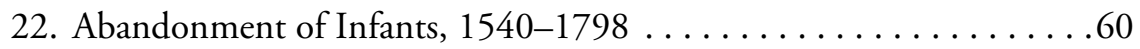


23. Suicides and Seasonality, $1542-1798 \ldots \ldots \ldots \ldots \ldots \ldots \ldots \ldots$

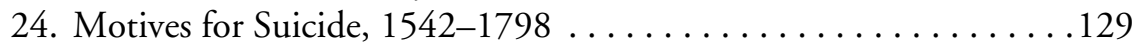

25. Civil Status of Suicides, 1542-1798, Version 1 . . . . . . . . . . . 149

26. Civil Status of Suicides, 1542-1798, Version $2 \ldots \ldots \ldots \ldots \ldots . .150$

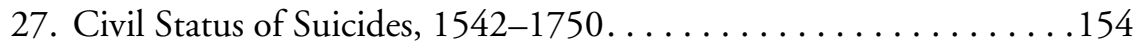

28. Employment Sectors for Male Suicides, $1542-1798 \ldots \ldots \ldots \ldots 156$

29. Employment Sectors for Female Suicides, 1542-1798 . . . . . . . . 157

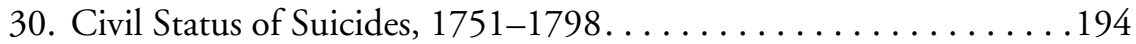

31. Civil Status of Suicides, $1751-1798 \ldots \ldots \ldots \ldots \ldots \ldots \ldots \ldots 4$

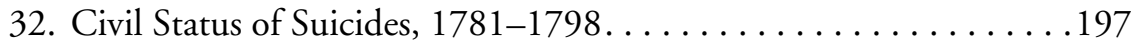

33. Pre-Revolutionary Civil Status of Suicides, 1793-1798 . . . . . . . . 199

34. Marital Status, Male and Female Suicides, 1542-1798 . . . . . . 215

35. Marital Status, Female Suicides, $1542-1798 \ldots \ldots \ldots \ldots \ldots .216$

36. Marital Status, Male Suicides, $1542-1798 \ldots \ldots \ldots \ldots \ldots \ldots .217$

37. Female Suicides Survived by Offspring . . . . . . . . . . . 242

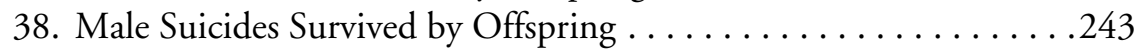

39. Age of Legitimate Offspring Left

by Male and Female Suicides, 1542-1798244

40. Family Motives Cited by Male and Female Suicides, 1542-1798. . .249 